\title{
Variations in the phenolic components of sorghum crop residues related to varietal and environmental differences
}

\author{
I. Mueller-Harvey', M. S. Dhanoa' , A. B. McAllan' ${ }^{1}$ and J. D. Reed² \\ 'AFRC Institute of Grassland and Environmental Research, Hurley SL6 5LR \\ ${ }^{2}$ Department of Meat and Animal Science, University of Wisconsin-Madison, 1675 Obseroatory Drive, Madison, \\ Wisconsin 53706-1284, USA
}

\section{Introduction}

Research to date has concentrated on improving the nutritive value of crop residues through chemical treatments. However, there is great natural variation in the nutritive value of untreated crop residues. General colorimetric measurements have indicated that phenolics are negatively correlated with digestibility. Environmental stress factors may contribute to the production of phenolics and sorghum varieties may differ in their genotype $X$ environment interaction.

The aim of this study was to investigate whether fingerprinting by high-performance liquid chromatography (HPLC) could be used to study the factors influencing phenolic composition in sorghum crop residues.

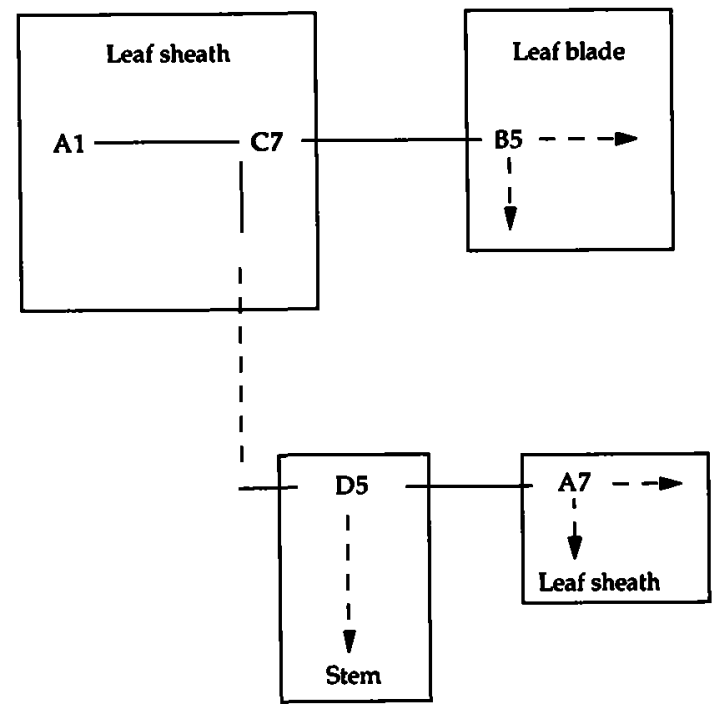

Figure 1 Cluster analysis of extractable phenolics from leaf blade (LB), leaf sheath (LS) and stem (ST) of several sorghum varieties grown at sites $A, B, C$ and $D$.

\section{Material and methods}

Fifteen sorghum varieties were grown using a completely randomized-block design at three different sites in Ethiopia. Crop residues were sampled at grain maturity and separated into leaf blade (LB), leaf sheath (LS) and stem (ST). Phenolics were extracted and separated by HPLC as described by Khazaal, Mueller-Harvey, McAllan, Osafo, Owen and Said (1993). HPLC peak heights were measured and analysed by single linkage cluster analysis (for further details see Mueller-Harvey and Dhanoa, 1991).

\section{Results}

Analysis of plant fractions

Cluster analysis yielded distinct groups of HPLC chromatograms from LB, LS and ST phenolics (Figure 1). Examples of chromatograms from one variety are given in Figure 2.

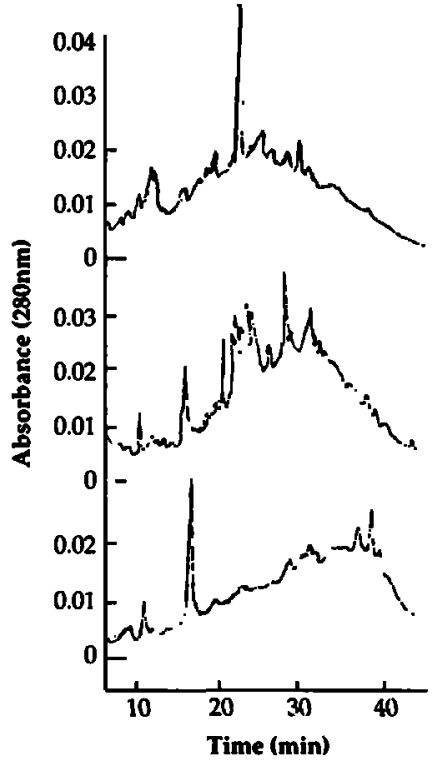

Figure 2 HILLC chromatograms of leaf blade (LB), leaf sheath (LS) and stem (ST) phenolics from lkinyaruka variety. 
Effects of environment and varicty on phenolic composition

Environment had greater effects on phenolic composition than variety. However, some large differences were also due to varietal effects. Both these effects were greatest in LS, followed by LB and smallest in ST phenolics. This suggests that a judicious selection of varieties based on leaf phenolics has great potential for improving the nutritive value of sorghum crop residues.

\section{Genotype $\times$ environment interactions}

Most varieties gave strong environment $X$ genotype interactions with respect to their phenolic composition. However, two bird resistant (BR) varieties seemed to have more stable compositions in different environments: in Figure 1 the Ikinyaruka variety clusters at two sites (A1 and $B 1$ ) and $X / 35: 24$ clusters at three sites (A5, B5, C5).

\section{Discussion}

Suggestion for a strategy to screen varieties

Differences between LS of BR and non-BR varieties are great at some but not all sites. Therefore, relatively fast measurements of red pigments (absorption measurements at $490 \mathrm{~nm}$ of aqueous ethanol extracts - Reed, Tedla and Kebede, 1987) should establish first if such differences are important at a given site. If this is the case, then varieties with a stable pattern of phenolic synthesis need to be identified. Such 'stable' varieties can then be selected further for improved digestibilities.
Conclusions

Strong genotype $X$ site interactions were found for the phenolics of sorghum leaves. There is some evidence that two varieties yielded much more stable phenolic compositions; these merit further study. Sorghum varieties with stable performance across environments are needed before being recommended to subsistence farmers. Alternatively, different genotypes may have to be selected for different environments.

\section{Acknowledgements}

Thanks are due to Dr Y. Kebede, Mr P. M. S. Blackwell, the International Livestock Centre for Africa (Addis Ababa) and the Ministry of Agriculture, Fisheries and Food, for kind assistance and the Overseas Development Administration for financial support.

\section{References}

Khazaal, K., Mueller-Harvey, I., McAllan, A. B., Osafo, E, Owen, E. and Said, A. N. 1993. Effect of harvesting at different stages of growth and long-term storage on phenolics in sorghum stover. In Animal production in deculoping conutries (ed. M. Gill, E. Owen, G. E. Pollott and T. L. J. Lawrence) Occosional publication, British Society of Animal Production no. 16. pp. 210-211.

Mueller-Harvey, I. and Dhanoa, M. S. 1991. Varietal differences amongst sorghum crop residues in relation to their phenolic HPLC-fingerprints and responses to different environments. Journal of the Science of Food and Agriculture 57: 199-216.

Reed, J. D., Tedla, A. and Kebede, Y. 1987. Phenolics, fibre and fibre digestibility in the crop residue from bird resistant and non-bird resistant sorghum varieties. Journal of the Science of Fond and Agriculture 39: 113-121. 